A) Check for updates

Cite this: Org. Biomol. Chem., 2017, 15, 9408

Received 10th October 2017, Accepted 24th October 2017

DOI: $10.1039 / c 7 o b 02505 j$

rsc.li/obc

\title{
Total syntheses of all tri-oxygenated 16-phytoprostane classes via a common precursor constructed by oxidative cyclization and alkyl- alkyl coupling reactions as the key steps $\uparrow$
}

\begin{abstract}
Jakub Smrček, Radek Pohl and Ullrich Jahn (D) *
A unified strategy for the total synthesis of the methyl esters of all phytoprostane (PhytoP) classes bearing two ring-oxygen atoms based on an orthogonally protected common precursor is described. Racemic $16-\mathrm{F}_{1 \mathrm{t}^{-}}, 16-\mathrm{E}_{1}$-PhytoP and their $\mathrm{C}-16$ epimers, which also occur as racemates in Nature, were successfully obtained. The first total synthesis of very sensitive $16-\mathrm{D}_{1 \mathrm{t}}$-PhytoP succeeded, however, it quickly isomerized to more stable, but so far also unknown $\Delta^{13}-16-D_{1 t}$-PhytoP, which may serve as a more reliable biomarker for D-type PhytoP. The dioxygenated cyclopentane ring carrying the $\omega$-chain with the oxygen functionality in the 16-position was approached by a radical oxidative cyclization mediated by ferrocenium hexafluorophosphate and TEMPO. The $\alpha$-chain was introduced by a new copper-catalyzed alkylalkyl coupling of a 6-heptenyl Grignard reagent with a functionalized cyclopentylmethyl triflate.
\end{abstract}

\section{Introduction}

Oxidative stress is one of the important and intensely studied topics in current medicine and life sciences. It describes a situation, where the redox equilibrium of a cell and its environment is imbalanced in favor of oxidants and by which reactive oxygen species (ROS) are unspecifically generated. This excess of ROS stabilizes by reaction with biologically important primary metabolites such as nucleic acids, proteins or lipids thus abrogating their functions. ${ }^{1,2}$ Clear evidence has been gathered that increased levels of oxidative stress are related to many human diseases.

Prostaglandins (PGs) are enzymatically formed by a radical reaction cascade as single enantiomers from the most prominent polyunsaturated fatty acid (PUFA) arachidonic acid regulating a wide range of biological processes (Scheme 1). ${ }^{3-5}$ However all PUFAs are essential parts of the cell membrane and react with ROS by radical reactions including peroxidation as well as fragmentation or cyclization cascades. ${ }^{6-9}$ Cyclic products of these autoxidative transformations are structural analogs of PGs. The best known and studied representatives are isoprostanes (IsoPs) produced from arachidonic (C20:4 $\omega-6)^{6,10}$ or eicosapentaenoic (C20:5 $\left.\omega-3\right)^{11,12}$ acids in animals

Institute of Organic Chemistry and Biochemistry, Czech Academy of Sciences, Flemingovo náměstí 2, 16610 Prague 6, Czech Republic.E-mail:jahn@uochb.cas.cz $\dagger$ Electronic supplementary information (ESI) available: Experimental procedures, analytical characterization and copies of ${ }^{1} \mathrm{H}$ and ${ }^{13} \mathrm{C}$ NMR spectra of all compounds. See DOI: 10.1039/c7ob02505j
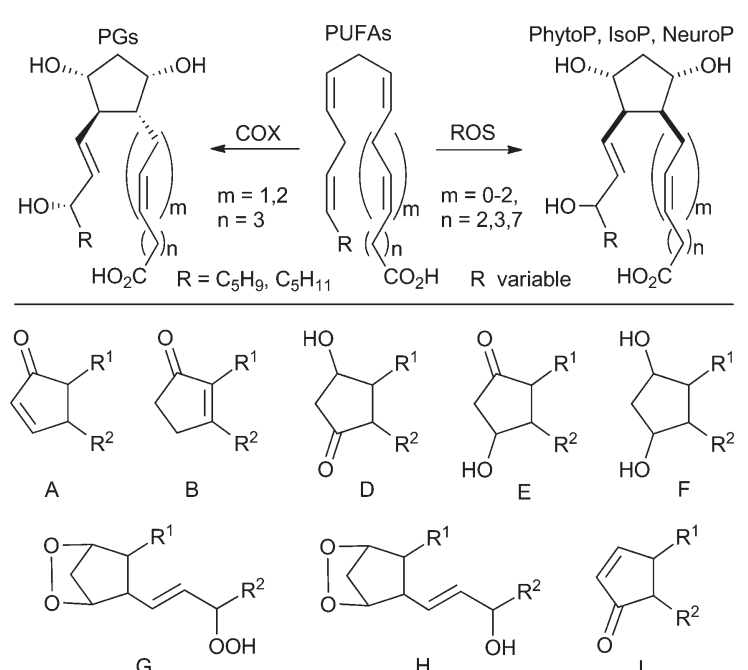

$\mathrm{R}^{1}=\alpha$-chain bearing $\mathrm{COOH}, \mathrm{R}^{2}=\omega$-chain

Scheme 1 Formation of cyclic PUFA metabolites and classes based on their ring substitution. $\mathrm{COX}=$ cyclooxygenase for arachidonic acid, $\mathrm{ROS}=$ reactive oxygen species.

and humans. Recently metabolites of docosahexaenoic acid (C22:6 $\omega$-3), named neuroprostanes (NeuroPs), were also discovered in the human brain. ${ }^{13}$ A number of biological activities of IsoPs and NeuroPs were reported. ${ }^{14}$

In the plant kingdom phytoprostanes (PhytoPs) were found as metabolites of $\alpha$-linolenic acid (C18:3 $\omega-3) .{ }^{8}$ PhytoPs are 
assumed to play an essential role in the protection and detoxification of plant cells and serve as a part of their oxidative injury-sensing system. ${ }^{15-17}$ A living cell is not required for their formation and the level and composition of PhytoP change during the processing of plant-originated raw materials in the food industry. ${ }^{18}$ Thus, they are recommended as suitable biomarkers of oxidative degradation in plant-derived edibles. ${ }^{19-26}$

The structural similarity of PhytoPs to PGs and IsoPs suggests possible bioactivities in humans and animals. It was demonstrated that the level of PhytoPs in the human body depends on the diet and also increases after a high consumption of $\alpha$-linolenic acid. ${ }^{27,28}$ However, only a few studies have been published in this field. Traidl-Hoffmann et al. reported that $\mathrm{E}_{1}-$ and $\mathrm{F}_{1}$-PhytoPs act similarly to endogenous PGs and modulate human dendritic cell function and T-cell polarization. ${ }^{29,30}$ The role of $\mathrm{E}_{1}$-PhytoP in pollen-caused allergies was subsequently studied in more detail. ${ }^{31,32}$

Because of the radical nature of their formation, PhytoPs occur in vivo as racemic mixtures of hardly separable regioand diastereomers and the natural material is therefore not useful for a thorough study of their biological effects. The total synthesis of individual stereoisomers is the only appropriate way to provide a material for the study of their biological activity. Since the discovery of PhytoPs in $1998^{8}$ more than ten total syntheses of individual PhytoPs have been published. $., 33,34$

Diversity oriented syntheses of PhytoPs are especially attractive for many biological investigations. So far, such approaches aimed at accessing the different diastereomers or side chain isomers for a given ring substitution pattern. For example, all eight diastereomers of $16-\mathrm{F}_{1 \mathrm{t}}$ and $9-\mathrm{F}_{1 \mathrm{t}}$ PhytoPs were published by Durand et al., ${ }^{35,36}$ which is based on a radical 5-exo cyclization of a sugar-based precursor. ${ }^{37}$ An analogous approach was recently applied to the total syntheses of $\mathrm{B}_{1}$-PhytoPs ${ }^{38,39}$ and 9-D $\mathrm{D}_{1 \mathrm{t}}$-PhytoP. ${ }^{40}$ An individual total synthesis of $16-\mathrm{E}_{1}$-PhytoP was also published, based on the Friedel-Crafts acylation of furan, followed by a Piancatelli rearrangement and attachment of the $\omega$-chain by 1,4-conjugate addition after enzymatic resolution. ${ }^{41}$ The total syntheses of ring-isomeric cyclopentenone PhytoP, namely 9 - and $16-\mathrm{B}_{1}$ - and $\mathrm{L}_{1}$-PhytoP as well as 9- $\mathrm{A}_{1}$ - and $9-\mathrm{J}_{1}$-PhytoP, were accomplished by the Vidari-Zanoni group, ${ }^{42,43}$ whereas Riera's group developed an individual approach to $16-\mathrm{B}_{1}$ - and $9-\mathrm{L}_{1}$-PhytoPs. ${ }^{44} \mathrm{~A}$ total synthesis of $16-\mathrm{D}_{1 \mathrm{t}}$-PhytoP was never accomplished. The only evidence for its occurrence stems from the transformation of a mixture of all possible $\mathrm{F}_{1}$-PhytoP isomers based on a procedure originally developed for an access to $\mathrm{PGD}_{2} \cdot{ }^{45}$ A $3: 1$ mixture of $\mathrm{D}_{1}$ - to $\mathrm{E}_{1}$ PhytoP isomers was obtained, which was not further separated and identified. ${ }^{46}$ This further highlights the need for selective approaches to these natural products for meaningful biological investigations. Considering that the diversity of biological activities of cyclic PUFA metabolites rather rests on the differential substitution patterns at the cyclopentane ring than on the side chain structure, we hypothesized that a unified approach allowing a simple simultaneous access to most possible ring oxygenation patterns of PhytoP may constitute a more promising and affordable approach than designing individual strategies to them (vide supra). Another benefit of such a unified approach is the possibility of attaching different types of $\alpha$-chains to the same $\omega$-chain-containing cyclic unit, $^{47,48}$ thus forming PhytoPs, IsoPs or NeuroPs with minimal effort.

We report here the total syntheses of $16-\mathrm{F}_{1 \mathrm{t}^{-}}, 16-\mathrm{E}_{1}$ - and $16-\mathrm{D}_{1 \mathrm{t}}-\mathrm{Phyto}$ and provide evidence that $16-\mathrm{D}_{1 \mathrm{t}}-\mathrm{PhytoP}$ will probably hardly be detectable in biological samples because of its facile isomerization to the so far unknown $\Delta^{13}-16-\mathrm{D}_{1 \mathrm{t}}{ }^{-}$ PhytoP, which represents therefore a potentially better observable metabolite in biological materials.

\section{Results and discussion}

The retrosynthesis of $16-\mathrm{F}_{1 \mathrm{t}^{-}}, 16-\mathrm{E}_{1^{-}}$and $16-\mathrm{D}_{1 \mathrm{t}}$-PhytoPs $1-3$ is based on common precursor $\mathbf{4}$, which can be easily transformed to all target compounds by simple deprotection, protection and oxidation reactions (Scheme 2). This orthogonally protected PhytoP structure 4 was envisaged to be obtained by copper(I)-catalyzed $\mathrm{C}\left(\mathrm{sp}^{3}\right)-\mathrm{C}\left(\mathrm{sp}^{3}\right) \operatorname{coupling}^{49}$ of a suitable $\alpha$-chain precursor and the substituted cyclopentane core 5 . An

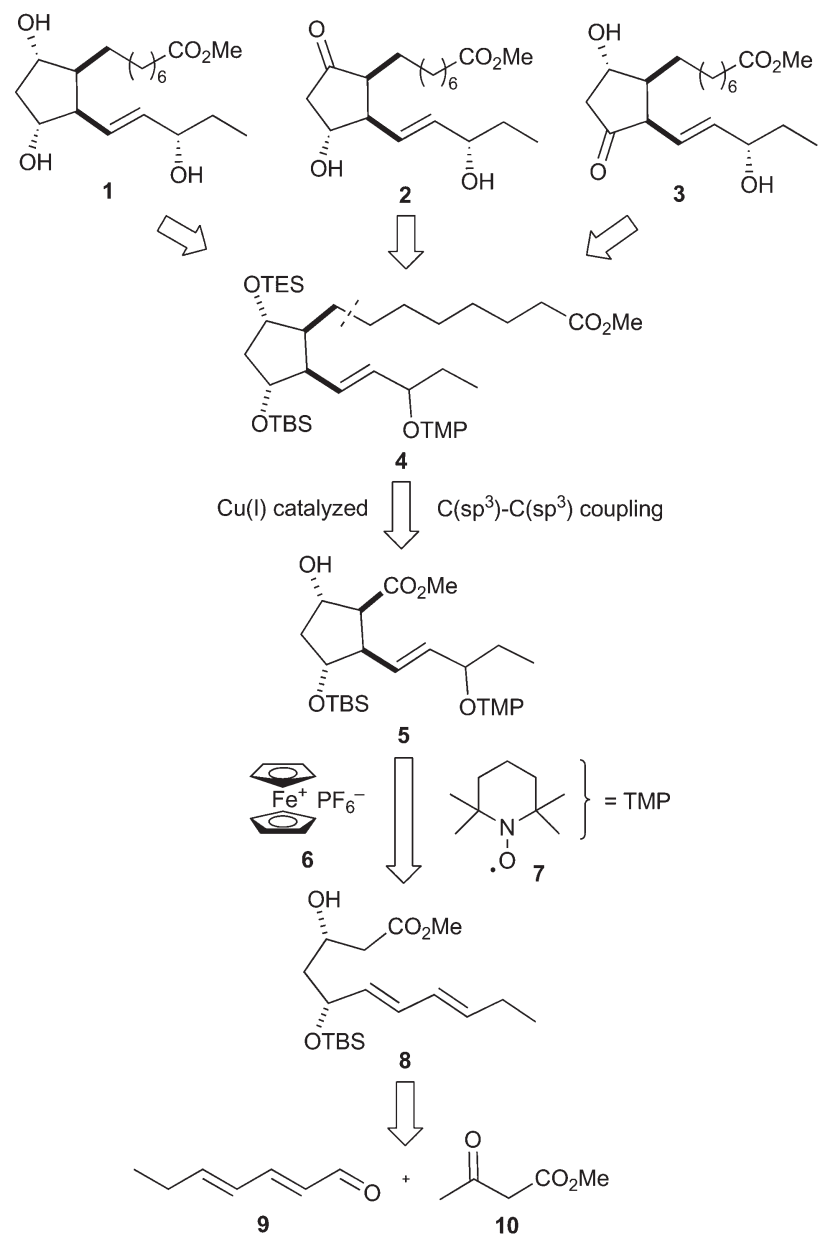

Scheme 2 Retrosynthetic analysis of $\mathrm{F}_{1 \mathrm{t}^{-}}, \mathrm{E}_{1^{-}}$and $\mathrm{D}_{1 \mathrm{t}}$-PhytoP. 
oxidative radical anion cyclization using ferrocenium hexafluorophosphate 6 and the stable radical 2,2,6,6-tetramethylpiperidine $N$-oxyl (TEMPO) 7 paves the way for construction of the central cyclic structure 5. Cyclization substrate $\mathbf{8}$ should be easily prepared from commercially available $(E, E)-2,4$-heptadienal (9) and methyl acetoacetate (10).

The total syntheses commenced with the preparation of cyclization precursor $\mathbf{8}$ in analogy to published procedures in three steps (Scheme 3). ${ }^{47,48}$ The vinylogous aldol addition of heptadienal $\mathbf{9}$ and acetoacetate $\mathbf{1 0}$ had to be performed with a somewhat larger excess of bases (1.3 equiv. NaH, 1.2 equiv. BuLi) than previously. Reduction of the carbonyl group at C-3 of hydroxy keto ester $\mathbf{1 1}$ proceeded with good yield and exclusive syn selectivity providing diol $\mathbf{1 2}$. The formation of monoprotected diol $\mathbf{8}$ was accomplished with equimolar amounts of tert-butyldimethylsilyl trifluoromethanesulfonate (TBSOTf) in the presence of 2,6-lutidine at low temperature.

The tandem radical cyclization/oxygenation was performed by deprotonating substrate 8 with an excess of base and the resulting 1,3-enediolate was subjected to single electron transfer (SET) oxidation, cyclization and oxygenation by treatment with ferrocenium hexafluorophosphate 6 and TEMPO 7. Applying these conditions to the cyclization of $\mathbf{8}$ gave cyclopentanes 5 in $49 \%$ and $47 \%$ yield, respectively (Table 1, entries 1 and 2). The diastereomeric ratio of $\mathbf{5 a}$ and $\mathbf{5 b}$ is dependent on the applied base. The formation of PG-like structure $\mathbf{5 b}$ is predominant when the deprotonation was caused by the stronger chelating magnesium species (Table 1, entry 2). Decreasing the chelating ability of magnesium by the addition of HMPA prior to deprotonation led to a reversed ratio being similar to that with LDA (Table 1, entry 3 vs. 1). Pentylzinc bromide induced an increase in the $\mathbf{5 a} / \mathbf{5 b}$ ratio, but low conversion was observed when the deprotonation was conducted at $-78{ }^{\circ} \mathrm{C}$ (Table 1 , entry 4). The conversion was better at higher temperature, but the stereoselectivity dropped (Table 1 , entry 5). A noticeable improvement was observed when DME was used as the solvent and the amount of HMPA was increased (Table 1, entries 8 and 9). Other attempts to affect the reaction were unsuccessful. A recently developed catalytic version of the cyclization ${ }^{50}$ proceeded with low yield and diastereoselectivity (not shown). Transmetalation of the dilithium 1,3-enediolate using $\mathrm{Ti}(\mathrm{OiPr})_{4}, \mathrm{Al}(\mathrm{OiPr})_{3}$ or $\mathrm{B}(\mathrm{OMe})_{3}$ resulted in no cyclization, but $\beta$-elimination and transesterification products were identified.

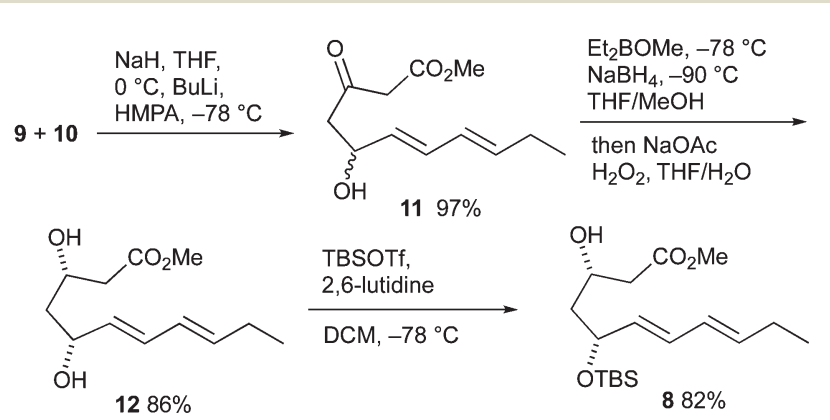

Scheme 3 Preparation of cyclization precursor 8.
Table 1 Oxidative radical cyclization/oxygenation of dihydroxy ester 8

\begin{tabular}{|c|c|c|c|c|c|}
\hline 8 & 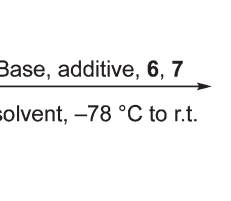 & 5a OTMP & OH & $5 b$ & \\
\hline Entry & Base & Additive $^{a}$ (equiv.) & Solvent & $5(\%)$ & $\mathbf{a}: \mathbf{b}^{b}$ \\
\hline 1 & LDA & LiCl, HMPA (6) & THF & 49 & $1.6: 1$ \\
\hline 2 & $t \mathrm{BuMgCl}, \mathrm{LDA}$ & HMPA (6) & THF & 47 & $1: 5$ \\
\hline 3 & $t \mathrm{BuMgCl}, \mathrm{LDA}$ & $\operatorname{HMPA}(6)^{c}$ & THF & 30 & $1.3: 1$ \\
\hline 4 & PentZnBr, ${ }^{d}$ LDA & HMPA (6) & THF & 16 & $3: 1$ \\
\hline 5 & PentZnBr ${ }^{e}$ LDA & HMPA (6) & THF & 42 & $1.5: 1$ \\
\hline 6 & LDA & LiCl, HMPA (12) & THF & 48 & $1.5: 1$ \\
\hline 7 & LDA & LiCl, TMEDA (9) & THF & 51 & $1.2: 1$ \\
\hline 8 & LDA & LiCl, HMPA (6) & DME & 55 & $1.6: 1$ \\
\hline 9 & LDA & LiCl, HMPA (12) & DME & 64 & $2: 1$ \\
\hline
\end{tabular}

${ }^{a} \mathrm{LiCl}$ is always 6 equiv. based on $8 .{ }^{b} \mathrm{dr}$ determined from the ${ }^{1} \mathrm{H}$ NMR spectra of an inseparable mixture. ${ }^{c}$ HMPA added prior to deprotonation. ${ }^{d}$ Deprotonation at $-78{ }^{\circ} \mathrm{C} .{ }^{e}$ Deprotonation at $25{ }^{\circ} \mathrm{C}$.

No reaction occurred and 8 was recovered when 12-crown-4 was used as an additive (not shown).

The significant effect of the metal cation can be traced to differentially strong chelation during the course of the cyclization (Scheme 4). Both, the dilithium and the magnesium 1,3enediolate I, are likely strongly chelated, however on SET oxidation the resulting radical anions behave significantly different. The lithium radical anion apparently equilibrates between the open form $\mathbf{I I}_{\mathbf{o}}$ and the chelated form $\mathbf{I I}_{\mathbf{c}}$ prior to cyclization, so that a mixture of cyclic radicals III and IV with low diastereoselectivity results, which stabilizes by oxygenation with 7 to cyclic esters $\mathbf{5 a}$ and $\mathbf{5 b}$. The magnesium radical anion is likely more stable in the chelated form $\mathbf{~ I I}_{\mathbf{c}}$ and therefore cyclizes predominately to cyclopentanecarboxylate $\mathbf{5 b}$.

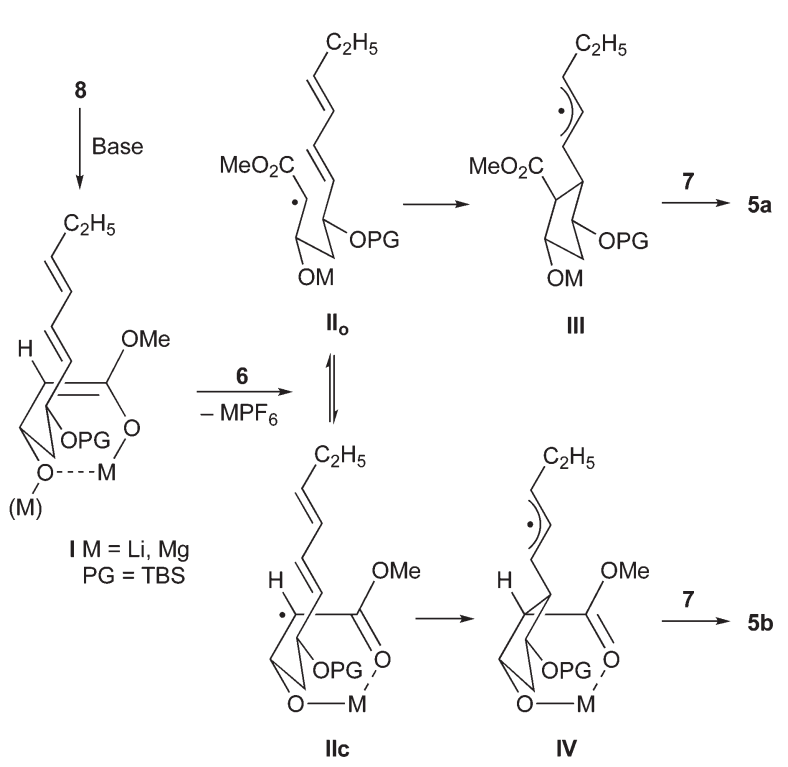

Scheme 4 Course of the radical cyclization/oxygenation of ester 8 . 
In contrast to the previous IsoP syntheses, ${ }^{47,48}$ where a free hydroxy group was mandatory, orthogonal protection was necessary to complete the unified approach to PhytoPs 1-3. Triethylsilyl (TES) protection of the free hydroxy group gave esters 13a and 13b, which were, however, only partially separable. Hypothesizing that the silylation of $\mathbf{5 a}$ might be significantly faster than that of $\mathbf{5 b}$ because of less steric interactions with the neighboring ester function, the amount of TESCl was reduced to the quantity of $\mathbf{5 a}$ in the mixture (Table 2). Indeed, the hydroxy group of $\mathbf{5 a}$ was preferably silylated and a separable mixture rich in diastereomer 13a was obtained (entry 1). A decrease in the temperature further increased the selectivity for silylation of the desired ester $\mathbf{5 a}$ (entries 2-4). In contrast, TES triflate reacted unselectively (not shown).

The ester group of 13a was transformed to triflate $\mathbf{1 5}$ in two steps (Scheme 5). Dibal-H in dichloromethane was optimal for the reduction to alcohol 14. In contrast, full deprotection of the TES group and partial deprotection of the TBS group occurred when $\mathrm{LiAlH}_{4}$ in THF was used. Alcohol 14 was converted to triflate $\mathbf{1 5}$ using triflic anhydride and 2,6-lutidine in good yield.

The crucial introduction of the $\alpha$-chain was performed by copper(I)-catalyzed alkyl-alkyl coupling. Initial experiments were fruitless and therefore a series of model reactions was performed with cyclohexylmethyl triflate as a model substrate and several alkyl halides bearing functionality that could be later transformed to an ester group (for details, see the ESI $\dagger$ ). Based on these results, the coupling reactions of $\omega$-alkenyl Grignard reagents $\mathbf{1 6}$ with triflate $\mathbf{1 5}$ were further studied (Table 3). 6-Heptenylmagnesium bromide 16a gave surprisingly only a low yield of the desired PhytoP precursor 17 and bromide 18 was the main product, which was unreactive in the coupling reaction (Table 3, entries 1 and 2). A switch of the Grignard reagent to the less nucleophilic chloride $\mathbf{1 6 b}$ prevented the triflate-halogen exchange largely and compound $\mathbf{1 7}$ comprising the complete skeleton was obtained in a reasonable yield (Table 3 , entry 3 ). It was subsequently found that the addition of lithium halides ${ }^{51}$ was beneficial to accelerate the coupling and to further reduce the formation of compound $\mathbf{1 8}$ (Table 3, entries 4 and 5). Surprisingly the bromide anion,

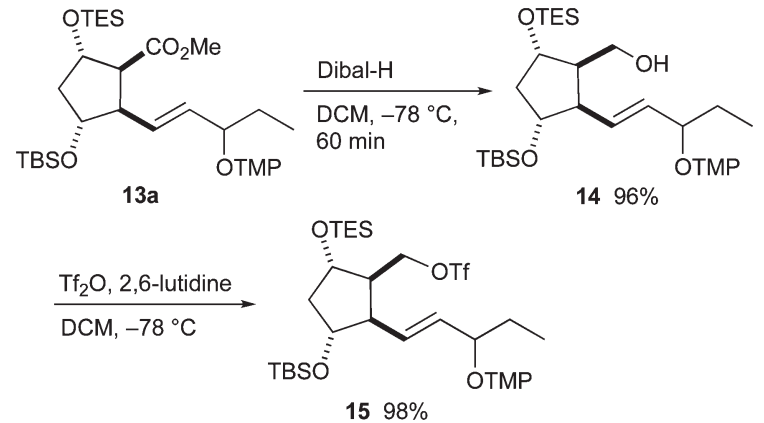

Scheme 5 Preparation of alkyl-alkyl coupling partner 15 from ester $13 a$.

Table $3 \mathrm{Cu}(\mathrm{l})$-Catalyzed alkyl-alkyl coupling of triflate 15 and Grignard reagents 16

\begin{tabular}{|c|c|c|c|c|c|c|}
\hline 15 & $\begin{array}{l}\begin{array}{l}30 \mathrm{~mol} \\
\text { additiv }\end{array} \\
\mathrm{XMg} \\
16 \mathrm{a} \\
16 \mathrm{~b}\end{array}$ & 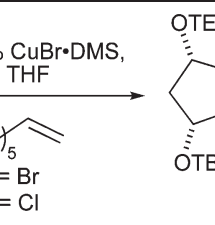 & ОтМР & OT & 18 & TMP \\
\hline ntry & 16 & Additive (equiv.) & $T\left({ }^{\circ} \mathrm{C}\right)$ & $t(\mathrm{~h})$ & $17(\%)$ & $18(\%)$ \\
\hline & $\mathbf{a}$ & - & 0 & 3 & 9 & 77 \\
\hline & $\mathbf{a}$ & - & -78 to r.t. & 24 & 15 & 78 \\
\hline & b & - & -78 to 0 & 12 & 63 & $24^{a}$ \\
\hline & b & $\operatorname{LiBr}(5)$ & -78 to -50 & 3 & 66 & $7^{a}$ \\
\hline & b & $\mathrm{LiCl}(5)$ & -78 to -50 & 3 & 71 & 0 \\
\hline
\end{tabular}

${ }^{a}$ Both chloride and bromide $\mathbf{1 8}$ were identified by NMR spectroscopy and ESI MS of the mixture.

stemming from LiBr, did not display the undesired substitution reactivity.

The central synthetic intermediate 4 was obtained from olefin 17 in four steps (Scheme 6). Hydroboration with 9-BBN using classical conditions or microwave heating provided the corresponding borane in almost quantitative yields, but the reaction time was reduced under microwave conditions. Its oxi-

Table 2 Diastereomer-selective TES protection of hydroxycyclopentanecarboxylates $\mathbf{5 a}$ and $\mathbf{5 b}$

\begin{tabular}{|c|c|c|c|c|c|c|c|}
\hline & & $5 a, b$ & $\begin{array}{l}\text { TESCI, } \\
\text { Imidazole }\end{array}$ & $\underbrace{\text { OTES }}_{\text {OTBS }}$ & $+\sum_{\Sigma}^{\text {OTES }}$ & & \\
\hline Entry & $5 \mathbf{a}: 5 \mathbf{b}^{a}$ & \multicolumn{2}{|c|}{ TESCl (equiv.) } & $T\left({ }^{\circ} \mathrm{C}\right)$ & Yield $^{b}(\%)$ & $13 \mathbf{a}: 13 \mathbf{b}^{a}$ & Unreacted $\mathbf{5 a}: \mathbf{5} \mathbf{b}^{a}$ \\
\hline 2 & $1.5: 1$ & 0.53 & & 0 & 90 & $5.4: 1$ & $1: 1.9$ \\
\hline 3 & $2: 1$ & 0.66 & & -20 & 80 & $7.5: 1$ & $1: 1.6$ \\
\hline 4 & $1.7: 1$ & 0.64 & & -60 & 95 & $6.2: 1$ & $1: 1.8$ \\
\hline
\end{tabular}

${ }^{a} \mathrm{dr}$ determined by ${ }^{1} \mathrm{H}$ NMR spectroscopy. ${ }^{b}$ Yield based on the applied amount of TESCl. 

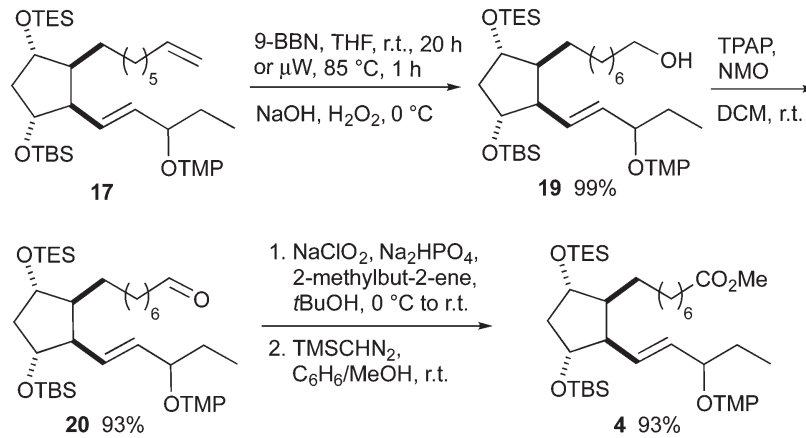

Scheme 6 Transformation of olefin 17 to orthogonally protected ester 4.

dation with basic hydrogen peroxide gave alcohol 19, which was oxidized to the corresponding acid using a two-step protocol consisting of Ley-Griffith oxidation to aldehyde 20 and subsequent Pinnick oxidation. Methyl ester $\mathbf{4}$ was prepared from the crude acid with (trimethylsilyl)diazomethane.

16- $\mathrm{F}_{1 \mathrm{t}}$-PhytoP methyl ester 1 was obtained from precursor 4 in three steps (Scheme 7). Oxidative removal of the tetramethylpiperidinyl group using $m \mathrm{CPBA}^{52}$ gave ketone 21 in almost quantitative yield. Although not executed here, an advantage of this strategy is the potential opportunity to reduce the carbonyl group enantioselectively. ${ }^{35,36}$ Since we focused on generating both $\mathrm{C}-16$ diastereomers, the Luche reduction was applied, which gave both C-16 epimers in a $1: 1.216-\mathrm{F}_{1 \mathrm{t}}$-/16-epi-16- $\mathrm{F}_{1 \mathrm{t}}$-PhytoP ratio. Both silyl groups were conserved when the reduction was performed at $-78{ }^{\circ} \mathrm{C}$, however, TES deprotection occurred on warming to $-10{ }^{\circ} \mathrm{C}$. The remaining protected hydroxy groups were liberated by reaction with TBAF. The methyl esters of $16-\mathrm{F}_{1 \mathrm{t}}-\mathrm{PhytoP} 1$ and its 16-epimer epi-1 were separable by standard column chromatography and the correct stereochemistry at C-16 was determined by the comparison of measured and published NMR spectra. ${ }^{35,36}$ The overall yield amounted to $13 \%$ over 15 steps.

The synthesis of $16-\mathrm{E}_{1}$-PhytoP methyl esters 2 started with alcohol 23 (Scheme 8). The hydroxy group was protected as TBS ether and the TES group was subsequently selectively
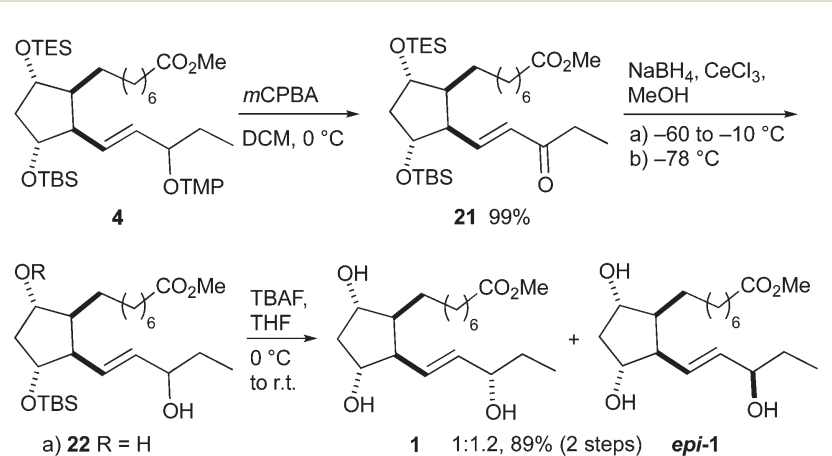

b) $23 \mathrm{R}=\mathrm{TES} 94 \%$

$1 \quad 1: 1.2,89 \%$ (2 steps) epi-1

Scheme 7 Completion of the total synthesis of $16-F_{1 t}-$ PhytoP 1 and 16-epi-16- $\mathrm{F}_{1 \mathrm{t}}$-PhytoP epi-1 methyl esters.
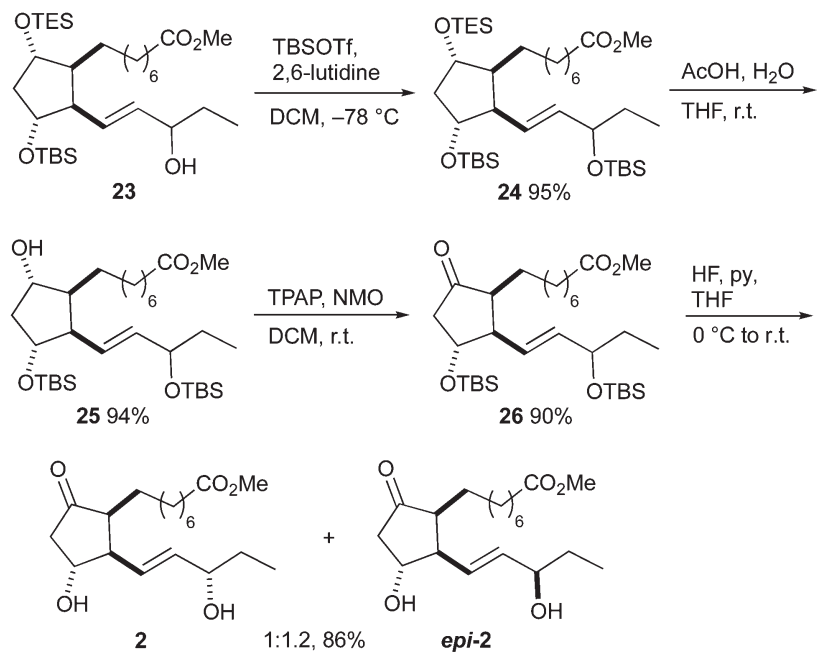

Scheme 8 Completion of the total synthesis of $16-E_{1}-P h y t o P 2$ and 16-epi-16- $\mathrm{E}_{1}$-PhytoP epi-2 methyl esters.

removed by acetic acid giving disilylated alcohol 25 . Ketone 26 was prepared by Ley-Griffith oxidation; using the Dess-Martin periodinane gave a slightly lower yield of $78 \%$. Hydrogen fluoride/pyridine proved to be the reagent of choice for the deprotection of the TBS groups. Separation of 16- $\mathrm{E}_{1}-\mathrm{PhytoP} 2$ and its 16-epimer epi-2 by flash column chromatography was possible. The stereochemistry at $\mathrm{C}-16$ was confirmed by comparison with the published NMR data. ${ }^{41}$ The epimeric ratio is in agreement with that observed in the synthesis of $\mathrm{F}_{1 \mathrm{t}}$-PhytoP methyl esters 1 and $\boldsymbol{e p i - 1}$. The overall yield was 9\% over 18 steps.

The D-classes of IsoPs and PGs are known for their low stability caused by the sensitive $\beta, \gamma$-unsaturated ketone functionality, ${ }^{6,53-55}$ therefore several protecting groups removable under mild conditions were tested for the synthesis of $16-\mathrm{D}_{1 \mathrm{t}}$-PhytoPs. The 1-ethoxyethoxy (EE) group was the only fruitful choice besides the methoxymethoxy (MOM) group. Protected $16-\mathrm{D}_{1 \mathrm{t}}$-PhytoP derivatives $29 \mathbf{a}$, b were synthesized in four steps from hydroxy ester 23 (Scheme 9). Selective removal of the TES group with acetic acid provided diol 22 . Introduction of the EE group using catalytic PPTS proceeded
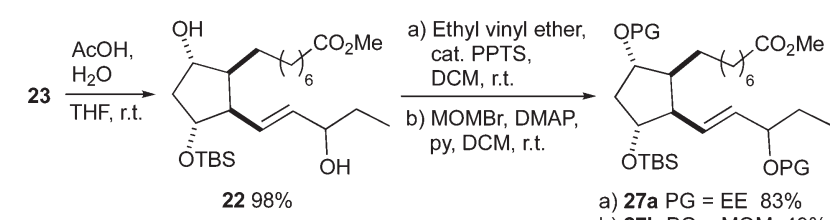

a) $27 \mathrm{a} P \mathrm{PG}=\mathrm{EE} \mathbf{8 3} \%$ b) $27 \mathrm{~b} P G=$ MOM $49 \%$
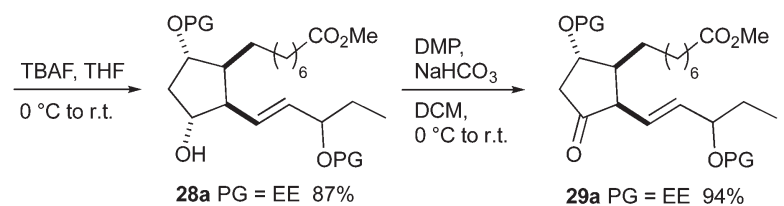

28a $P G=E E \quad 87 \%$
28b PG $=$ MOM $69 \%$

29a $P G=E E 94 \%$

29b $P G=$ MOM $97 \%$

Scheme 9 Synthesis of EE- and MOM-protected 16- $\mathrm{D}_{1 \mathrm{t}}$-PhytoP derivatives 29a and 29b. 


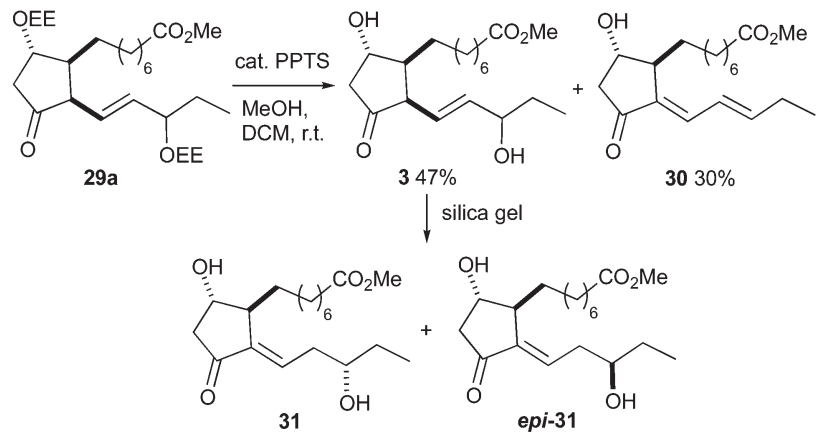

Scheme 10 Access to $16-D_{1 t}-$ PhytoP methyl ester 3 by deprotection and its isomerization to $\Delta^{13}-16-D_{1 t}$-PhytoP methyl ester 31 .

smoothly to give 27a, whereas MOM protection giving $27 \mathbf{b}$ was less efficient. Removal of the remaining silyl group in 27a, b was executed by TBAF and afforded free 12-alcohols 28a, b. Their Dess-Martin oxidation to ketones 29a, b worked almost quantitatively.

The final deprotection was performed by using catalytic amounts of PPTS (Scheme 10). Removal of the EE group of ketone 29a was completed at room temperature over three hours and gave a 1.5:1 mixture of 16- $\mathrm{D}_{1 \mathrm{t}}$-PhytoP methyl esters 3 and 16-deoxy- $\Delta^{13,15}-16-\mathrm{D}_{1 \mathrm{t}}$-PhytoP methyl ester 30. The MOM deprotection of ketone $29 \mathrm{~b}$ proceeded very slowly at room temperature. Heating to reflux led to a hardly separable mixture, in which neither the expected $\mathrm{D}_{1 \mathrm{t}}$-PhytoP 3 nor dienyl PhytoP 30 were identified. The C-16 epimers of 3 were not separable by column chromatography and moreover, partial isomerization to more stable $\Delta^{13}-16-\mathrm{D}_{1 \mathrm{t}}$-PhytoP methyl esters 31 and epi-31 occurred during chromatographic purification. The isomerization could be promoted by treatment with silica gel and C-16 epimers 31 and $\boldsymbol{e p i - 3 1}$ were isolated in overall 4\% yield over 19 steps. The unequivocal assignment of the individual C-16 epimers was impossible. Nevertheless, we assume that the less polar epimer is $\Delta^{13}-16$-epi-16- $\mathrm{D}_{1 \mathrm{t}}$-PhytoP (epi-31) in analogy to the polarities of 16-epi-16- $\mathrm{F}_{1 \mathrm{t}}$-PhytoP and 16-epi-16$\mathrm{E}_{1}$-PhytoPs. This hypothesis is supported by common signal patterns observed in the ${ }^{13} \mathrm{C}$ NMR spectra of compounds $29 \mathbf{b}$, $\mathbf{3}$ and $\mathbf{3 1}$ (for details see the ESI $\dagger$ ). Moreover, epi-3 is thus the major C-16 epimer of 3 being in agreement with the epimeric ratio obtained in the Luche reduction of $\mathbf{2 1}$ and observed in the total syntheses of $16-\mathrm{F}_{1 \mathrm{t}^{-}}$and $16-\mathrm{E}_{1}$-PhytoPs 1 and 2.

\section{Conclusions}

A new strategy for the diversity-oriented synthesis of all trioxygenated 16-PhytoP classes, based on an orthogonally protected common precursor was developed. The key step for the formation of the dioxygenated cyclopentane ring was a radical oxidative cyclization mediated by ferrocenium hexafluorophosphate and TEMPO, which also introduced the oxygen functionality in the 16-position of the $\omega$-chain. The complete carbon skeleton was assembled by a copper-catalyzed alkyl- alkyl coupling of a 6-heptenyl Grignard reagent and the properly functionalized cyclopentylmethyl triflate. 16- $\mathrm{F}_{1 \mathrm{t}}-\mathrm{PhytoP}$ methyl ester $\mathbf{1}$ and its epimer $\boldsymbol{e p i - 1}$ were obtained in $13 \%$ yield over 15 steps. The synthesis of the methyl esters of $16-\mathrm{E}_{1}$ PhytoP 2 and its C-16 epimer epi-2 took 18 steps and the overall yield amounted to $9 \%$. The first total synthesis of $16-\mathrm{D}_{1 \mathrm{t}}$-PhytoP methyl ester 3 resulted in an inseparable mixture of its C-16 epimers and their more stable isomerization products $\mathbf{3 1}$ and $\boldsymbol{e p i - 3 1}$, which can be prepared by complete isomerization in $4 \%$ yield over 19 steps. The reported strategy will facilitate the simultaneous access to the majority of oxidatively formed cyclic metabolites derived from linolenic acid. Total syntheses of cyclopentenoic PhytoP can also be envisaged based on this approach. Moreover, the strategy will also be applicable to approach cyclic metabolites of the other major $\omega$-3 PUFAs, eicosapentaenoic or docosahexaenoic acids. Investigations along these lines are under way in these laboratories.

\section{Conflicts of interest}

There are no conflicts to declare.

\section{Acknowledgements}

Generous financial support by the Institute of Organic Chemistry and Biochemistry, Czech Academy of Sciences (RVO:61388963) is gratefully acknowledged.

\section{Notes and references}

1 Oxidative Stress in Vertebrates and Invertebrates: Molecular Aspects on Cell Signaling, ed. T. Farooqui and A. A. Farooqui, Wiley, Hoboken, 2012.

2 Oxidative Stress: Diagnostics, Prevention, and Therapy, ed. S. Andreescu and M. Hepel, ACS, Washington, DC, 2011.

3 Prostaglandins: Biochemistry, Functions, Types, and Roles, ed. G. M. Goodwin, Nova Science Publishers, New York, 2010.

4 S. Das, S. Chandrasekhar, J. S. Yadav and R. Grée, Chem. Rev., 2007, 107, 3286-3337.

5 Prostaglandins, Leukotrienes, and Other Eicosanoids: From Biogenesis to Clinical Application, ed. F. Marks and G. Fürstenberger, Wiley-VCH, Weinheim, 1999.

6 U. Jahn, J.-M. Galano and T. Durand, Angew. Chem., Int. Ed., 2008, 47, 5894-5955.

7 U. Jahn, J.-M. Galano and T. Durand, Prostaglandins, Leukotrienes Essent. Fatty Acids, 2010, 82, 83-86.

8 S. Parchmann and M. J. Mueller, J. Biol. Chem., 1998, 273, 32650-32655.

9 T. Durand, V. Bultel-Poncé, A. Guy, S. El Fangour, J.-C. Rossi and J.-M. Galano, Biochimie, 2011, 93, 52-60.

10 J. D. Morrow, K. E. Hill, R. F. Burk, T. M. Nammour, K. F. Badr and L. J. Roberts, Proc. Natl. Acad. Sci. U. S. A., 1990, 87, 9383-9387. 
11 L. Gao, H. Yin, G. L. Milne, N. A. Porter and J. D. Morrow, J. Biol. Chem., 2006, 281, 14092-14099.

12 J. Nourooz-Zadeh, B. Halliwell and E. E. Änggård, Biochem. Biophys. Res. Commun., 1997, 236, 467-472.

13 L. J. Roberts, T. J. Montine, W. R. Markesbery, A. R. Tapper, P. Hardy, S. Chemtob, W. D. Dettbarn and J. D. Morrow, J. Biol. Chem., 1998, 273, 13605-13612.

14 J.-M. Galano, E. Mas, A. Barden, T. A. Mori, C. Signorini, C. De Felice, A. Barrett, C. Opere, E. Pinot, E. Schwedhelm, R. Benndorf, J. Roy, J.-Y. Le Guennec, C. Oger and T. Durand, Prostaglandins Other Lipid Mediators, 2013, 107, 95-102.

15 T. Durand, V. Bultel-Poncé, A. Guy, S. Berger, M. J. Mueller and J.-M. Galano, Lipids, 2009, 44, 875-888.

16 N. A. Eckardt, Plant Cell, 2008, 20, 495-497.

17 M. J. Mueller, Curr. Opin. Plant Biol., 2004, 7, 441-448.

18 J. Collado-González, T. Durand, F. Ferreres, S. Medina, A. Torrecillas and A. Gil-Izquierdo, Lipid Technol., 2015, 27, 127-130.

19 J.-M. Galano, J. C.-Y. Lee, C. Gladine, B. Comte, J.-Y. Le Guennec, C. Oger and T. Durand, Biochim. Biophys. Acta, Mol. Cell Biol. Lipids, 2015, 1851, 446-455.

20 J. Collado-González, S. Medina, T. Durand, A. Guy, J.-M. Galano, A. Torrecillas, F. Ferreres and A. GilIzquierdo, Food Chem., 2015, 178, 212-220.

21 M. E. Yonny, A. Rodríguez Torresi, C. Cuyamendous, G. Réversat, C. Oger, J.-M. Galano, T. Durand, C. Vigor and M. A. Nazareno, J. Agric. Food Chem., 2016, 64, 8296-8304.

22 A. M. Carrasco-Del Amor, J. Collado-González, E. Aguayo, A. Guy, J.-M. Galano, T. Durand and A. Gil-Izquierdo, $R S C$ Adv., 2015, 5, 51233-51241.

23 A. M. Carrasco-Del Amor, J. Collado-González, E. Aguayo, A. Guy, J.-M. Galano, T. Durand and A. Gil-Izquierdo, $R S C$ Adv., 2016, 6, 25669-25669.

24 A. M. Carrasco-Del Amor, E. Aguayo, J. Collado-González, A. Guy, J.-M. Galano, T. Durand and A. Gil-Izquierdo, Food Chem., 2016, 211, 869-875.

25 J. Marhuenda, S. Medina, A. Díaz-Castro, P. MartínezHernández, S. Arina, P. Zafrilla, J. Mulero, C. Oger, J.-M. Galano, T. Durand, F. Ferreres and A. Gil-Izquierdo, J. Agric. Food Chem., 2015, 63, 9022-9028.

26 J. Collado-González, A. Moriana, I. F. Girón, M. Corell, S. Medina, T. Durand, A. Guy, J.-M. Galano, E. Valero, T. Garrigues, F. Ferreres, F. Moreno, A. Torrecillas and A. Gil-Izquierdo, LWT-Food Sci. Technol., 2015, 64, 997-1003.

27 A. E. Barden, K. D. Croft, T. Durand, A. Guy, M. J. Mueller and T. A. Mori, J. Nutr., 2009, 139, 1890-1895.

28 K. Karg, V. M. Dirsch, A. M. Vollmar, J.-L. Cracowski, F. Laporte and M. J. Mueller, Free Radical Res., 2007, 41, 25-37.

29 C. Traidl-Hoffmann, V. Mariani, H. Hochrein, K. Karg, H. Wagner, J. Ring, M. J. Mueller, T. Jakob and H. Behrendt, J. Exp. Med., 2005, 201, 627-636.

30 J. Gutermuth, M. Bewersdorff, C. Traidl-Hoffmann, J. Ring, M. J. Mueller, H. Behrendt and T. Jakob, J. Allergy Clin. Immunol., 2007, 120, 293-299.
31 S. Oeder, F. Alessandrini, O. F. Wirz, A. Braun, M. Wimmer, U. Frank, M. Hauser, J. Durner, F. Ferreira, D. Ernst, M. Mempel, S. Gilles, J. T. M. Buters, H. Behrendt, C. Traidl-Hoffmann, C. Schmidt-Weber, M. Akdis and J. Gutermuth, Allergy, 2015, 70, 1450-1460.

32 C. Blume, E. J. Swindle, S. Gilles, C. Traidl-Hoffmann and D. E. Davies, Tissue Barriers, 2015, 3, e1062316.

33 E. Jahn, T. Durand, J.-M. Galano and U. Jahn, Chem. Listy, 2014, 108, 301-319.

34 A. Guy, S. Flanagan, T. Durand, C. Oger and J.-M. Galano, Front. Chem., 2015, 3, 41, DOI: 10.3389/fchem.2015.00041.

35 S. El Fangour, A. Guy, V. Despres, J.-P. Vidal, J.-C. Rossi and T. Durand, J. Org. Chem., 2004, 69, 2498-2503.

36 S. El Fangour, A. Guy, J.-P. Vidal, J.-C. Rossi and T. Durand, Tetrahedron Lett., 2003, 44, 2105-2108.

37 A. Roland, T. Durand, D. Egron, J.-P. Vidal and J.-C. Rossi, J. Chem. Soc., Perkin Trans. 1, 2000, 245-251.

38 S. El Fangour, A. Guy, J.-P. Vidal, J.-C. Rossi and T. Durand, J. Org. Chem., 2005, 70, 989-997.

39 E. Pinot, A. Guy, A.-L. Guyon, J.-C. Rossi and T. Durand, Tetrahedron: Asymmetry, 2005, 16, 1893-1895.

40 E. Pinot, A. Guy, A. Fournial, L. Balas, J.-C. Rossi and T. Durand, J. Org. Chem., 2008, 73, 3063-3069.

41 A. R. Rodríguez and B. W. Spur, Tetrahedron Lett., 2003, 44, 7411-7415.

42 R. Beretta, M. G. Gallotti, U. Penne, A. Porta, J. F. G. Romero, G. Zanoni and G. Vidari, J. Org. Chem., 2015, 80, 1601-1609.

43 A. Porta, F. Chiesa, M. Quaroni, M. Persico, R. Moratti, G. Zanoni and G. Vidari, Eur. J. Org. Chem., 2014, 21112119.

44 A. Vazquez-Romero, X. Verdaguer and A. Riera, Eur. J. Org. Chem., 2013, 1716-1725.

45 E. E. Nishizawa, W. L. Miller, R. R. Gorman, G. L. Bundy, J. Svensson and M. Hamberg, Prostaglandins, 1975, 9, 109121.

46 M. Krischke, C. Loeffler and M. J. Mueller, Phytochemistry, 2003, 62, 351-358.

47 U. Jahn and E. Dinca, J. Org. Chem., 2010, 75, 44804491.

48 U. Jahn and E. Dinca, Chem. - Eur. J., 2009, 15, 58-62.

49 C. Maaliki, E. Thiery and J. Thibonnet, Eur. J. Org. Chem., 2017, 209-228.

50 F. Kafka, M. Holan, D. Hidasová, R. Pohl, I. Císařová, B. Klepetářová and U. Jahn, Angew. Chem., Int. Ed., 2014, 53, 9944-9948.

51 K. Nakata, C. Feng, T. Tojo and Y. Kobayashi, Tetrahedron Lett., 2014, 55, 5774-5777.

52 T. Inokuchi and H. Kawafuchi, Tetrahedron, 2004, 60, 11969-11975.

53 Y. Brinkmann, C. Oger, A. Guy, T. Durand and J.-M. Galano, J. Org. Chem., 2010, 75, 2411-2414.

54 P. S. Foss, C. J. Sih, C. Takeguchi and H. Schnoes, Biochemistry, 1972, 11, 2271-2277.

55 G. L. Bundy, D. R. Morton, D. C. Peterson, E. E. Nishizawa and W. L. Miller, J. Med. Chem., 1983, 26, 790-799. 